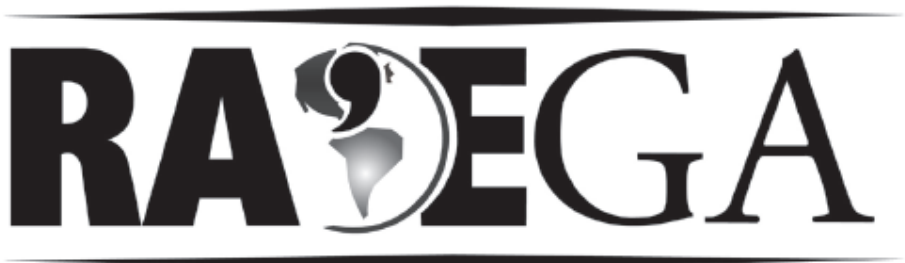

O ESPAÇO GEOGRÁFICO EM ANÁLISE

\title{
Estimativa da Vazão Máxima da Bacia Hidrográfica do Rio Canguiri através do Método de Ven Te Chow
}

\section{Estimate of Maximum flow of river watershed Canguiri through the method of Ven Te Chow}

\author{
Rita de Cássia Bianchi ${ }^{1}$ \\ Nivaldo Eduardo Rizzi ${ }^{2}$ \\ Rafael Zoboli Guimarães ${ }^{3}$ \\ Richardson Guenther Schechi ${ }^{4}$
}

\section{RESUMO}

O estudo da chuva excedente ou escoamento superficial direto é fundamental para análises hidrológicas, pois é a parte responsável pelas cheias em pequenas bacias impermeabilizadas. $O$ presente trabalho avalia a vazão máxima da bacia hidrográfica do rio Canguiri para os anos de 1976, 1984 e 1999, com o método de Ven Te Chow - Soil Conservation Service (SCS) um modelo hidrológico de transformação de chuvas em vazões. A vazão de pico foi estimada para os tempos de recorrência ( $\operatorname{Tr}$ ) igual a 3, 5, 10,15, 20, 25 e 50 anos. Com a notável redução das áreas florestadas e um crescimento das áreas urbanizadas, houve um aumento na vazão de pico para todos os Trs, mostrando assim o alto grau de compactação do solo na bacia hidrográfica.

Palavras-Chave: Vazão Máxima; Número Hidrológico; Curva Número; Bacia do rio Canguiri.

\footnotetext{
${ }^{1}$ Engenheira Florestal. Universidade Federal do Paraná, Curitiba, Paraná, Brasil. Curitiba, Paraná, Brasil. e-mail: risobianchi@yahoo.com.br

${ }^{2}$ Engenheiro Florestal. Universidade Federal do Paraná, Curitiba, Paraná, Brasil. e-mail:niva@ufpr.br

${ }^{3}$ Engenheiro Ambiental. Universidade da Região de Joinvile, Joinvile, Santa Catarina, Brasil. e-mail: rzguimaraes@gmail.com

${ }^{4}$ Engenheiro Florestal. Universidade Federal do Paraná, Curitiba, Paraná, Brasil. e-mail: engrichardson@gmail.com
} 


\section{ABSTRACT}

The study of rainfall excess or direct runoff is critical for hydrological analysis, it is the party responsible for floods in small basins waterproofed. This paper evaluates the maximum flow of the river basin Canguiri for the years 1976, 1984 and 1999, with the method of Ven Te Chow - Soil Conservation Service (SCS) a hydrological model of transformation of rainfall into stream flow. The discharge peak was estimated to recurrence time $(\operatorname{Tr})$ of 3, 5, 10, 15, 20, 25 and 50 years for study of the basin. With the notable reduction of forested areas and the growth of urbanized areas, there was an increase in peak discharge for all Trs, thus demonstrating the high degree of soil compaction in the watershed.

Keywords: Maximum flow; Number Hydrological; Curve Number; Canguiri River Basin.

\section{INTRODUÇÃO}

A Região Metropolitana de Curitiba (RMC), criada em 1973, é uma região de crescentes mudanças e com alto grau de urbanização. Inicialmente a RMC era composta por 14 municípios com uma população de 907.391 habitantes, atualmente possui 26 municípios com 2.768.394 habitantes (COMEC, 2011).

Esse crescimento desorganizado e acelerado modifica a estrutura do solo com a redução de áreas florestadas, diminuindo, dessa forma, a capacidade de infiltração do solo, aumentando o escoamento superficial e por consequência levando a região a ter picos de vazão maior e com mais frequência. Estudos mais detalhados para verificar os picos de vazão em áreas de riscos e a capacidade do rio de suportar tal vazão podem contribuir para o planejamento urbano reduzindo os riscos ambientais.

Frequentemente é utilizado para a transformação de chuva em vazão o método racional, aplicável a pequenas bacias urbanas, e os métodos baseados na teoria do hidrograma unitário, utilizados em bacia de maior porte (JABUR, 2010, p. 17). Dentre os modelos de previsão de vazão máxima se tem o método de Ven Te Chow que é também um modelo hidrológico de transformação de chuva em vazão.

O método permite analisar áreas que não possuem dados fluviométricos, calculando vazões de enchentes decorrentes da precipitação incidente, 
atribuindo um tempo de recorrência, estabelecendo assim, relação com o risco hidrológico para a determinada chuva crítica ou vazão de projetos na previsão de enchentes e elaboração de obras hidráulicas (FENDRICH, 2008, p.03). Neste método a chuva efetiva, ou seja, a chuva excedente ou escoamento superficial é a maior responsável pelas vazões de cheias em pequenas bacias urbanizadas.

O método proposto por Ven Te Chow empregou o Método do Soil Conservation Service (SCS) para a avaliação da chuva efetiva $\left(\mathrm{P}_{\mathrm{e}}\right)$. O método da Curva Número, desenvolvido pelo Soil Conservation Service (SCS) dos Estados Unidos da América - E. U. A. possibilita a obtenção das informações do comportamento do escoamento superficial em função do uso, do tipo e da umidade antecedente do solo das bacias hidrográficas, permitindo avaliar os impactos do uso do solo na resposta hidrológica da bacia.

O presente estudo teve por objetivo a estimativa da vazão máxima da bacia hidrográfica do rio Canguiri, pelo método de Ven Te Chow, em três períodos distintos, 1976, 1984 e 2009. A análise multitemporal estudada corresponde à época de grande desenvolvimento dos municípios que compõem a área de estudo e é, justamente, pelo avanço desordenado nesse período que esses anos foram trabalhados. Podendo, dessa forma, mostrar as causas que a impermeabilização do solo pode causar na vazão.

\section{ÁREA DE ESTUDO}

A área de estudo, Bacia do rio Canguiri, localiza-se na Região Metropolitana de Curitiba (RMC), próxima as nascentes do rio Iguaçu, na Serra do Mar. Constitui-se em um dos mananciais de abastecimento de água da cidade de Curitiba, contribuindo em volume de água para a o reservatório do Iraí. Nesta bacia estão inseridos 4 municípios da RMC como se pode observar na Figura (1), sendo eles: Colombo (39,8\%), Pinhais (31,1\%), Campina Grande do Sul (15,3\%) e Quatro Barras (13,5\%). Trata-se de uma bacia de quarta ordem com o comprimento do rio principal igual a $8,56 \mathrm{~km}$ é uma sub-bacia pequena, com 17,94 km² de área (JACOBS, 2002, p. 37). 
De acordo com Jacobs (2002, p.59), a bacia tem uma densidade de drenagem (Dd) considerada alta, de $2,72 \mathrm{~km} / \mathrm{km}^{2}$. Por ser uma área localizada às margens da rodovia BR-116, houve um aumento na urbanização e diminuição da superfície ocupada pela floresta.

A bacia hidrográfica, de acordo com Bigarella; Salamuni (1962), encontra-se situada no Primeiro Planalto Paranaense o qual é formado por relevo suave, com altitudes médias em torno de 900 metros, composto, principalmente por sedimentos da Formação Guabirotuba. Apresenta dois tipos de depósitos do quaternário de natureza distinta: o mais recente Holoceno que é constituído por depósitos de várzeas e aluviais contendo áreas com cascalhos e argilas; e o mais antigo e mais extenso Pleistoceno, que é composto de depósitos argilosos da formação Guabirotuba de espessura de 60 $\mathrm{cm}$ até poucos metros de profundidade.

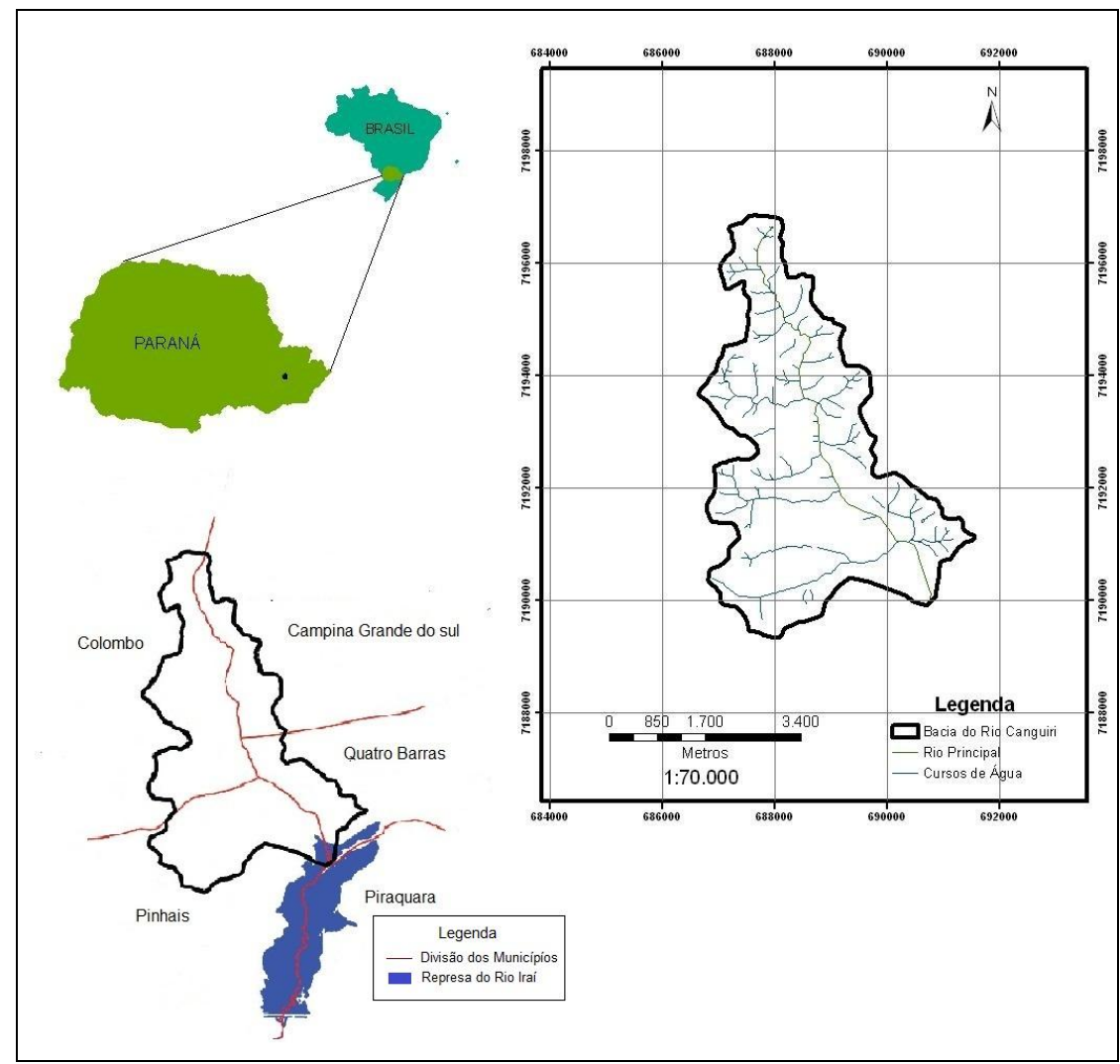

FIGURA 1: Localização da Bacia do Rio Canguiri 
Os Cambissolos e Latossolos e suas associações são predominantes na região. Porém, na bacia também há os Organossolos háplicos nas regiões de menor altitude (vales) (FIGURA 2).

Por possuir solos rasos e a formação geológica Guabirotuba em quase toda a sua extensão, a bacia hidrográfica do Rio Canguiri, em locais sem cobertura florestal e com um mínimo de declividade, apresenta forte tendência para gerar erosões. Solos originados a partir da formação Guabirotuba são solos que possuem em sua constituição, preferencialmente, argilominerais, assim conhecido como "material expansivo". São materiais que possuem limites de liquidez elevados e alta plasticidade. Quando secos são duros, mas perdem facilmente sua resistência quando absorvem água (FELIPE, 2011, p. 11).

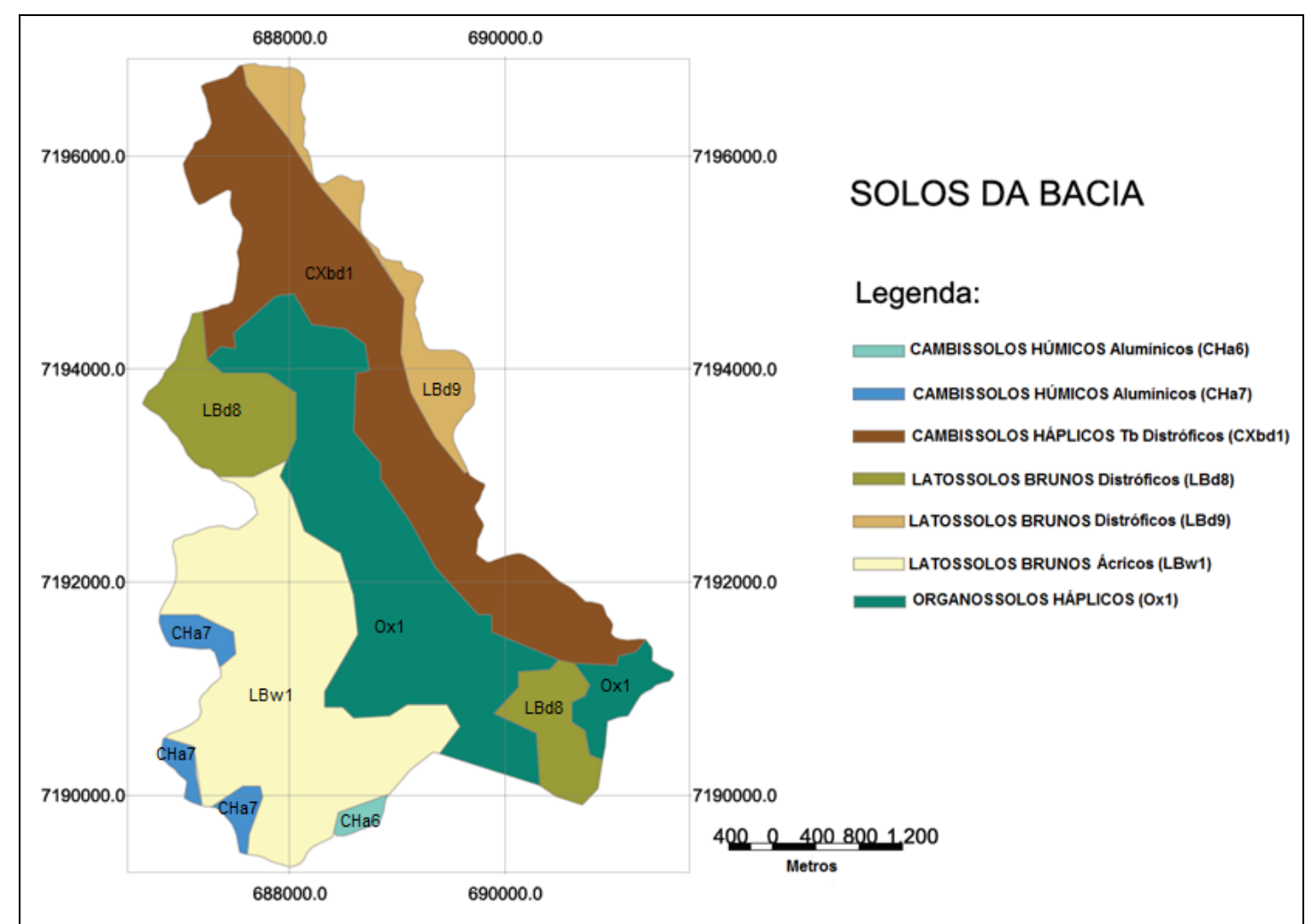

FIGURA 2: Mapa de Solo da Bacia do Rio Canguiri

Fonte: Adaptado de BHERING e SANTOS (2008) 


\section{MATERIAIS E MÉTODOS}

Os dados trabalhados da cobertura do solo, como tipologias e áreas, foram feitos e descritos por Jacobs (2002, p.146).

\section{Parâmetros do Método de Ven Te Chow (Soil Conservation Service)}

De acordo com Fendrich (2008, p. 28), o método permite analisar a altura da chuva efetiva $(\mathrm{Pe})$ considerando o tipo e cobertura do solo e a quantidade da chuva incidente. Assim para o cálculo da Pe foi empregado a fórmula utilizada no Método do Soil Conservation Service (SCS), dos Estados Unidos da América.

O método proposto por Ven Te Chow, conforme Nunes; Fiori (2007, p. 143) estabelece que a chuva efetiva, denominada de chuva excedente é responsável pelas vazões de cheias principalmente em bacias de pequenas escalas e urbanizadas. Assim, a vazão máxima pode ser expressa pela equação (1).

$$
Q_{\max }=\frac{A X_{*} Y . Z}{3,6}
$$

onde:

$\mathrm{Q}_{\text {máx }}=$ vazão máxima em $\mathrm{m}^{3} / \mathrm{s}$;

$\mathrm{A}=$ área da bacia em $\mathrm{km}^{2}$;

$\mathrm{X}=$ fator de deflúvio, igual à razão da precipitação efetiva pela duração da chuva $(\mathrm{Pe} / \mathrm{td})$;

$\mathrm{Y}=$ fator climático, igual à unidade nos locais onde há fórmula base regionalizada;

$Z$ = fator de redução do tempo de pico (admensional)

A chuva efetiva ou precipitação excedente é calculada de acordo com a equação 2 (FENDRICH, 2008, p. 31):

$$
P_{\theta}=\frac{\left(P_{p}-5080 / N+50,8\right)^{2}}{P_{p}+20320 / N-203_{\imath} 2} \quad \text { equação (2) }
$$

onde:

$\mathrm{P}_{\mathrm{e}}=$ precipitação excedente $(\mathrm{mm})$;

$\mathrm{P}_{\mathrm{p}}=$ chuva total $(\mathrm{mm})$;

$\mathrm{N}$ = Número de deflúvio (Curva Número) 
A chuva total ou precipitação incidente $\left(P_{p}\right)$ é obtida pela multiplicação da intensidade pluviométrica pelo tempo de duração estabelecido para diferentes tempos de recorrência: $P_{p}=i_{m} * t d$ (Quadro 1).

O tempo de recorrência ( $\mathrm{Tr}$ ) é decido pelo risco hidrológico aceitável para a comunidade; para obras hidráulicas o Tr já é estipulado e seu valor varia de acordo com o tipo de ocupação da área (FENDRICH, 2008, p. 04).

As chuvas intensas são determinadas pela seguinte equação (FENDRICH, 2003, p. 07):

$$
i_{m}=\frac{K \cdot T^{m}}{\left(t+t_{0}\right)^{n}}
$$

onde:

$\mathrm{i}_{\mathrm{m}}=$ intensidade pluviométrica $(\mathrm{mm} / \mathrm{h})$

$\mathrm{t}=$ tempo de duração da chuva (horas)

$\mathrm{Tr}=$ tempo de recorrência (anos)

$\mathrm{K}, \mathrm{t}_{\mathrm{o}}, \mathrm{m}, \mathrm{n}=$ parâmetros a determinar para a estação.

Como a bacia está localizada próximo ao município de Piraquara a equação da intensidade pluviométrica utilizada foi à obtida por Fendrich (2003, p. 16) para o Município de Piraquara no ano de 1989. Com os valores dos parâmetros da equação (3) iguais a: $\mathrm{m}-0,12 ; \mathrm{n}-0,859 ; \mathrm{K}-1537,80 ; \mathrm{t}_{\mathrm{o}}-17$. A validação das equações feitas por Fendrich (2003, p.9) é feita para cada ano de recorrência avaliando o erro padrão porcentual obtido para cada equação parcial.

No Quadro (1) estão representadas as intensidades da chuva e a chuva total. 
QUADRO 1 - Intensidade Pluviométrica, Chuva Total (Pp) para os respectivos Tempos de Recorrência (Tr)

\begin{tabular}{|c|c|c|c|}
\hline $\operatorname{td}(\min )$ & $t d(h)$ & $\mathrm{i}(\mathrm{mm} / \mathrm{h})$ & $\mathrm{Pp}(\mathrm{mm})$ \\
\hline \multicolumn{4}{|l|}{$\operatorname{Tr} 3$ anos } \\
\hline 20 & 0,33 & 78,90 & 26,037 \\
\hline 40 & 0,67 & 54,43 & 36,470 \\
\hline 60 & 1,00 & 42,04 & 42,040 \\
\hline 80 & 1,33 & 34,48 & 45,853 \\
\hline 100 & 1,67 & 29,35 & 49,012 \\
\hline 120 & 2,00 & 25,63 & 51,256 \\
\hline 140 & 2,33 & 22,80 & 53,117 \\
\hline 160 & 2,67 & 20,57 & 54,911 \\
\hline 210 & 3,50 & 16,61 & 58,129 \\
\hline 240 & 4,00 & 14,93 & 59,715 \\
\hline \multicolumn{4}{|l|}{$\operatorname{Tr} 5$ anos } \\
\hline 20 & 0,33 & 83,89 & 27,68 \\
\hline 40 & 0,67 & 57,87 & 38,78 \\
\hline 60 & 1,00 & 44,70 & 44,70 \\
\hline 80 & 1,33 & 36,66 & 48,75 \\
\hline 100 & 1,67 & 31,20 & 52,11 \\
\hline 120 & 2,00 & 27,25 & 54,50 \\
\hline 140 & 2,33 & 24,24 & 56,47 \\
\hline 160 & 2,67 & 21,87 & 58,38 \\
\hline 210 & 3,50 & 17,66 & 61,80 \\
\hline 240 & 4,00 & 15,87 & 63,49 \\
\hline \multicolumn{4}{|l|}{$\operatorname{Tr} 10$ anos } \\
\hline 20 & 0,33 & 91,16 & 30,08 \\
\hline 40 & 0,67 & 62,89 & 42,14 \\
\hline 60 & 1,00 & 48,57 & 48,57 \\
\hline 80 & 1,33 & 39,83 & 52,98 \\
\hline 100 & 1,67 & 33,91 & 56,63 \\
\hline 120 & 2,00 & 29,61 & 59,22 \\
\hline 140 & 2,33 & 26,34 & 61,37 \\
\hline 160 & 2,67 & 23,76 & 63,45 \\
\hline 210 & 3,50 & 19,19 & 67,16 \\
\hline 240 & 4,00 & 17,25 & 69,00 \\
\hline \multicolumn{4}{|l|}{$\operatorname{Tr} 15$ anos } \\
\hline 20 & 0,33 & 95,71 & 31,58 \\
\hline 40 & 0,67 & 66,03 & 44,24 \\
\hline 60 & 1,00 & 51,00 & 51,00 \\
\hline 80 & 1,33 & 41,82 & 55,62 \\
\hline 100 & 1,67 & 35,60 & 59,45 \\
\hline 120 & 2,00 & 31,09 & 62,18 \\
\hline 140 & 2,33 & 27,65 & 64,43 \\
\hline 160 & 2,67 & 24,95 & 66,61 \\
\hline 210 & 3,50 & 20,15 & 70,51 \\
\hline 240 & 4,00 & 18,11 & 72,44 \\
\hline
\end{tabular}

\begin{tabular}{|c|c|c|c|}
\hline $\operatorname{td}(\mathrm{min})$ & $\operatorname{td}(h)$ & $\mathrm{i}(\mathrm{mm} / \mathrm{h})$ & $\mathrm{Pp}(\mathrm{mm})$ \\
\hline \multicolumn{4}{|l|}{$\operatorname{Tr} 20$ anos } \\
\hline 20 & 0,33 & 99,07 & 32,69 \\
\hline 40 & 0,67 & 68,35 & 45,79 \\
\hline 60 & 1,00 & 52,79 & 52,79 \\
\hline 80 & 1,33 & 43,29 & 57,58 \\
\hline 100 & 1,67 & 36,85 & 61,54 \\
\hline 120 & 2,00 & 32,18 & 64,36 \\
\hline 140 & 2,33 & 28,63 & 66,70 \\
\hline 160 & 2,67 & 25,82 & 68,95 \\
\hline 210 & 3,50 & 20,85 & 72,99 \\
\hline 240 & 4,00 & 18,75 & 74,98 \\
\hline \multicolumn{4}{|l|}{$\operatorname{Tr} 25$ anos } \\
\hline 20 & 0,33 & 101,76 & 33,58 \\
\hline 40 & 0,67 & 70,20 & 47,04 \\
\hline 60 & 1,00 & 54,22 & 54,22 \\
\hline 80 & 1,33 & 44,46 & 59,14 \\
\hline 100 & 1,67 & 37,85 & 63,21 \\
\hline 120 & 2,00 & 33,05 & 66,11 \\
\hline 140 & 2,33 & 29,40 & 68,51 \\
\hline 160 & 2,67 & 26,52 & 70,82 \\
\hline 210 & 3,50 & 21,42 & 74,97 \\
\hline 240 & 4,00 & 19,25 & 77,02 \\
\hline \multicolumn{4}{|l|}{$\operatorname{Tr} 50$ anos } \\
\hline 20 & 0,33 & 110,58 & 36,49 \\
\hline 40 & 0,67 & 76,29 & 51,12 \\
\hline 60 & 1,00 & 58,92 & 58,92 \\
\hline 80 & 1,33 & 48,32 & 64,27 \\
\hline 100 & 1,67 & 41,13 & 68,69 \\
\hline 120 & 2,00 & 35,92 & 71,84 \\
\hline 140 & 2,33 & 31,95 & 74,45 \\
\hline 160 & 2,67 & 28,82 & 76,96 \\
\hline 210 & 3,50 & 23,28 & 81,47 \\
\hline 240 & 4,00 & 20,92 & 83,70 \\
\hline
\end{tabular}

\section{Enquadramento hidrológico dos solos}

Os solos são classificados conforme a sua suscetibilidade a erosão e a produção de escoamento (MENDES FILHO; VENDRAME; CARVALHO, 2007, p. 3455). A curva número é obtida de acordo com o uso e as características dos grupos hidrológicos de cada tipo de solo (FENDRICH, 2008, p. 31), considerando que os solos com propriedades semelhantes (espessura, textura, conteúdo de matéria orgânica, estrutura e grau de expansão quando saturados) terão respostas parecidas a um aguaceiro (SARTORI, 2004, p. 26) 
citando (USBR, 1977). A partir da textura dos solos e de sua espessura se pode enquadrar os solos em classes $A, B, C$ e $D$ conforme metodologia do (ábaco) (REYES, 2010, p. 58) citando (SOIL SURVEY STAFF, 2006), (Figura $3)$.

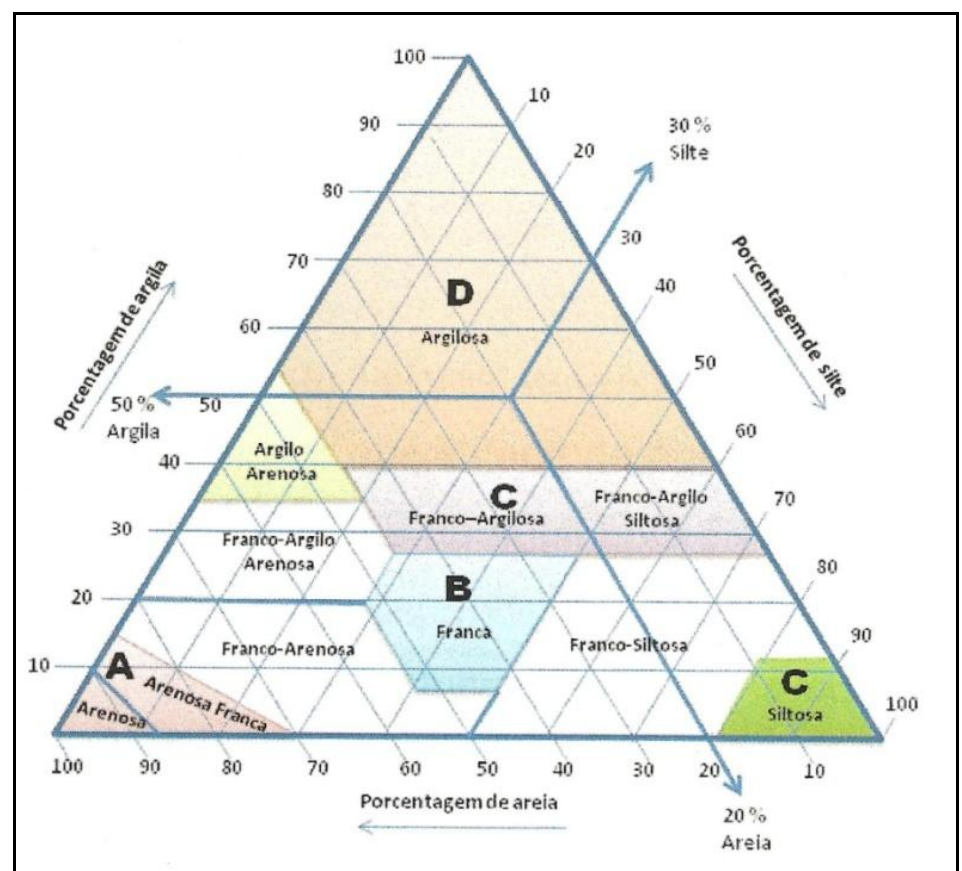

FIGURA 3 - Classes Texturais Básicas dos Solos

Fonte: Adaptada de USDA, Soil Survey Staff (2006 citado por Reyes 2010)

Para a determinação da curva número $(\mathrm{CN})$ teve como base o mapa de solo atualizado pela Embrapa em 2008 e a classificação textural. Tanto os Latossolos como os Cambissolos estão classificados como textura argilosa e os Organossolos sem classificação textural conforme (BHERING; SANTOS, 2008 , p. 55). Os Cambissolos, mesmo com um percentual na ordem de 27,18 da área ocupada, são considerados como um solo de baixa infiltração $(0$ - 1,3 $\mathrm{mm} / \mathrm{h}$ ) por ser referenciado à classificação equivalente aos solos orgânicos (DONE) (GOMES; FENDRICH, 1991, p. 31) Sendo assim, o grupo hidrológico a qual pertence à bacia hidrográfica do Rio Canguiri é o grupo "D", (Tabela 1). 
TABELA 1 - Distribuição Percentual das Classes de Solos e seus Respectivos Grupos Hidrológicos

\begin{tabular}{|c|c|c|c|}
\hline TIPO DE SOLO & ÁREA (\%) & $\begin{array}{c}\text { ÁBACO - CLASSES } \\
\text { TEXTURAIS }\end{array}$ & GRUPO HIDROLÓGICO \\
\hline $\begin{array}{l}\text { Cambissolos Úmicos alumínicos } \\
\qquad(\mathrm{CHa} 6+\mathrm{CHa} 7)\end{array}$ & 3,18 & Textura Argilosa & D \\
\hline $\begin{array}{l}\text { Cambissolos Háplicos Tb distróficos } \\
\text { (CXbd1) }\end{array}$ & 26,88 & Textura Argilosa & $\mathrm{D}$ \\
\hline $\begin{array}{c}\text { Latossolos Brunos distróficos } \\
\text { (LBd8 + LBd9) }\end{array}$ & 16,23 & Textura Argilosa & $\mathrm{D}$ \\
\hline $\begin{array}{l}\text { Latossolos Brunos acrícos } \\
\text { (LBw1) }\end{array}$ & 26,53 & Textura Argilosa & D \\
\hline $\begin{array}{l}\text { Organossolos Háplicos } \\
\qquad(\mathrm{O} 1)\end{array}$ & 27,18 & $\begin{array}{c}\text { sem classificação de } \\
\text { textura }\end{array}$ & D ou $E$ \\
\hline
\end{tabular}

Tipologias de uso do solo para obtenção das Curvas Número

Os Números representativos do complexo "Solos Hidrológicos", utilizados pelo método do Soil Conservation Service para representar diferentes tipos e uso do solo, condições de superfícies, foram denominados "Número Hidrológico" ou "Curva Número". Jacobs (2002, p. 127) classificou os usos do solo de todas as sub-bacias da Bacia do Alto Iguaçu as quais foram adaptadas para a classificação feita pelo método SCS, conforme descrito a seguir:

TIPO I - FLORESTA OMBRÓFILA MISTA MONTANA: tem como característica a ocorrência do Pinheiro do Paraná (Araucaria angustifolia). Inicialmente se formam os capões em pequenas depressões sendo sucedido pelos estágios arbóreos avançados da vegetação secundária, conhecido como capoeirão. $\mathrm{Na}$ tabela de classificação esse tipo de cobertura pode ser considerado como Florestas Densas de Alta Transpiração.

TIPO $\|$ - Floresta OMbrófila Mista - Sistema de VegetaçÃo SECUNDÁRIA: é a vegetação que surge logo após as alterações antrópicas (destruição da floresta e abandono do terreno) e ou naturais (incêndios), sendo característica o aparecimento de capoeirinhas, estágios sucessionais secundários. Classificada como capoeira com presença de espécies arbustivas de pequeno porte, com instalação inicial feita por gramíneas com condição média de infiltração. 
TIPO III - RefLorestamento: inclui os povoamentos homogêneos e heterogêneos de pinus e eucaliptos, devido à constante exploração inadequada durante os anos. Com condição hidrológica média por haver cortes irregulares.

TIPO IV - ESTEPE GRAMínEO LENHOSA: ocupam as áreas mais planas, os campos ou várzeas são constituídas por um pequeno número de espécies adaptadas às inundações periódicas. Classificada como pastagem velha com arbustos e gramados tratados em más condições.

TIPO V - FloRESTA OMBrófILA MISTA AluVIAL: conhecidas como florestas de galerias, floresta bastante abertas de porte baixo com sub-bosque quase inexistente ou sem sub-bosque, classificada como Florestas Esparsas.

TIPO VI - USO DA TERRA PARA AGRICULTURA: áreas de floresta que foram substituídas por áreas agrícolas, principalmente por haras, condomínios e chácaras. Classificadas como terrenos cultivados regularmente, cultivo com fileiras retas.

TIPO VII - ÁREAS URBANAS: área de uso intensivo, com grande parte da terra coberta por estruturas, inclui cidades, vilas, áreas de rodovias, serviços de transporte, energia e comunicação, fábricas, supermercados, complexos industriais e comerciais. Classificada como área residencial, lotes menores que $500 \mathrm{~m}^{2}$, com taxa de impermeabilização de $65 \%$.

TIPO VIII - ÁREAS COM ÁGUA: todos os corpos de d'água como rios, reservatórios, lagos.

O mapa de uso do solo para o ano de 2009, Figura (4), foi feito com apoio de levantamento de campo e com imagem multiespectral do satélite RAPIDEYE do ano de 2009, com resolução de $5 \mathrm{~m}$, providas pela empresa SENOGRAFIA Sensoriamento Remoto Ltda. A imagem foi digitalizada na projeção UTM, datum sad 69 no fuso $22^{\circ}$ S e classificada no programa gvSIG, exportada no formato "shape" e, no mesmo programa, convertida em mapa temático. Para os anos de 1976 e 1984 não ha mapas, apenas dados de áreas em quilômetros quadrados e porcentagem feita por Jacobs (2002). 


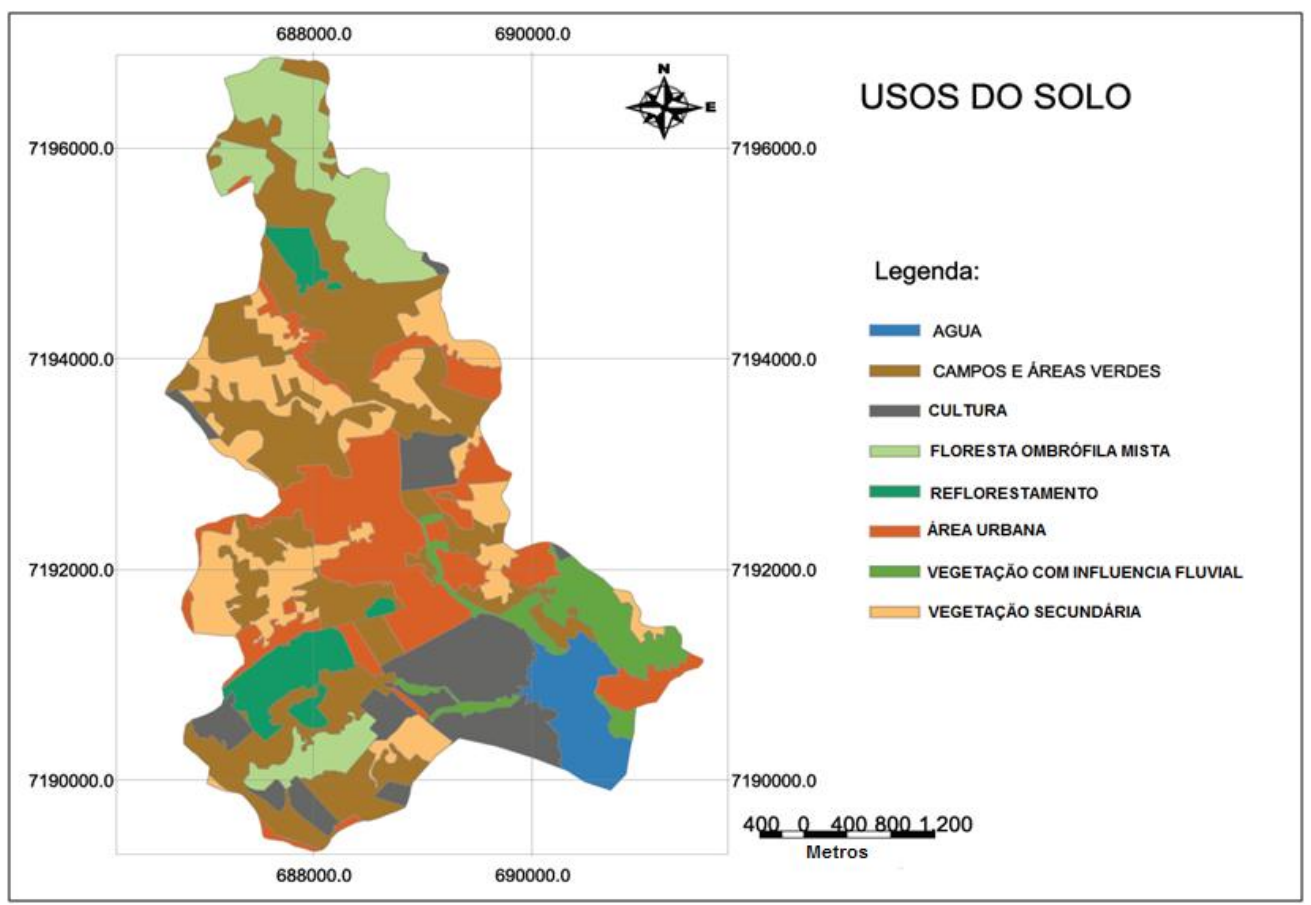

Figura 4 - Mapa de usos do solo na Bacia Hidrográfica do Rio Canguiri para o ano de 2009 Fonte: Imagem de satélite fornecida pela Empresa Senografia (2009)

Os tipos de uso do solo, bem como a sua alteração ao longo dos três períodos estudados nesse trabalho podem ser observados na (Tabela 2). Os valores de $\mathrm{CN}$ encontrados na Tabela (2) são valores das tabelas propostas por Sartori (2004, p. 29) citando Rawls et. al (1996); proposta por Fendrich (2008; p. 37) citando Departamento de Água e Energia Elétrica (1979); Fendrich (2008, p. 32) citando Wilken (1978), e Fendrich (2008, p. 38) citando Soil Conservation Service (1975).

Os valores tabelados de $\mathrm{CN}$ são relativos às condições de saturação normal de umidade no solo (NII), ou seja, condição intermediária entre o ponto de murcha permanente e o de saturação máxima do solo (FENDRICH, 2008, p. 35). Os valores de $\mathrm{CN}$ para as condições de solo seco, mas não em ponto de murcha permanente (NI) e para solos quase saturados (NIII) são determinados de acordo com as equações 4 e 5 :

$$
\begin{array}{ll}
N I=\frac{4,2 \cdot N_{I I}}{10-0,058 \cdot N_{I I}} & \text { equação (4) } \\
N I I I=\frac{23 \cdot N_{I I}}{10+0,13 \cdot N_{I I}} & \text { equação (5) }
\end{array}
$$

onde: 
$\mathrm{N}_{\| l}=$ Número da $\mathrm{CN}$ tabelado nas condições normais de umidade antecedente.

Na Tabela (3) está o valor médio da Curva Número para o período estudado. A CN média foi determinada pela média ponderada entre as áreas correspondentes de cada tipologia juntamente com o valor da CN, por exemplo, o valor médio de NI para o ano de 1976 é igual a:

$\left(48^{\star} 3,84+57^{\star} 2,15+47^{*} 0+67^{\star} 7,21+69^{\star} 2,07+75^{*} 0,5+83^{*} 2,17+100^{*} 0\right) / 17,9=64$. E assim para todos os outros valores de $\mathrm{CN}$.

TABELA 2 - Valores da Curva Número para diferentes recobrimentos do solo

\begin{tabular}{l|c|c|c|c|c}
\hline \multicolumn{1}{c|}{} & \multicolumn{5}{c}{ GRUPO HIDROLÓGICO DO SOLO } \\
\hline \multicolumn{1}{c}{ TIPO DE USO DO SOLOS } & A & B & C & D & E \\
\hline TIPO I - Florestas Densas de alta Transpiração & 26 & 52 & 62 & 69 & - \\
\hline $\begin{array}{l}\text { TIPO II - Copoeira com presença de espécies } \\
\text { arbustivas de pequenos porte, Florestas } \\
\text { Normais }\end{array}$ & 36 & 60 & 70 & 76 & - \\
\hline TIPO III - Reflorestamento & 30 & 42 & 55 & 68 & 78 \\
\hline $\begin{array}{l}\text { TIPO IV - Pastagem velha com arbustos/ } \\
\text { gramados tratados em más condições }\end{array}$ & $60 / 72$ & $66 / 72$ & $75 / 78$ & $82 / 84$ & $87 / 88$ \\
\hline TIPO V - Florestas Esparsas & 46 & 68 & 78 & 84 & - \\
\hline $\begin{array}{l}\text { TIPO VI - Terrenos Cultivados Regularmente; } \\
\text { Cultivo com fileiras retas }\end{array}$ & 64 & 76 & 84 & 88 & - \\
\hline $\begin{array}{l}\text { TIPO VII - Áreas residencial, lotes menores } \\
\text { que } 500 \text { m² com taxa de impermeabilização } \\
\text { de } 65 \%\end{array}$ & 77 & 85 & 90 & 92 & - \\
\hline TIPO VIII - Área com água & 100 & 100 & 100 & 100 & 100 \\
\hline \begin{tabular}{l} 
M. \\
\hline
\end{tabular}
\end{tabular}

Fonte modificada de Rawls et al.(1996); Soil Conservation Service (1975), Departamento de águas e energia (1979) e de Wilken (1978)

TABELA 3 - Tabela resumida para o cálculo de CN para os anos estudados

\begin{tabular}{|c|c|c|c|c|c|c|c|c|c|}
\hline \multirow{2}{*}{ TIPOLOGIAS DE USO DOS SOLOS } & \multicolumn{2}{|c|}{1976} & \multicolumn{2}{|c|}{1984} & \multicolumn{2}{|c|}{2009} & \multicolumn{3}{|c|}{ CURVA NÚMERO } \\
\hline & $\mathrm{Km}^{2}$ & $\%$ & $\mathrm{Km}^{2}$ & $\%$ & $\mathrm{Km}^{2}$ & $\%$ & $\mathrm{NI}$ & $\mathrm{NII}$ & $\mathrm{NIII}$ \\
\hline Floresta Ombrófila Mista Montana & 3,84 & 21,40 & 0,86 & 4,79 & 1,86 & 10,36 & 48 & 69 & 84 \\
\hline Vegeteção Secundária & 2,15 & 11,98 & 3,74 & 20,85 & 2,60 & 14,49 & 57 & 76 & 88 \\
\hline Reflorestamento & 0,00 & 0,00 & 0,96 & 5,35 & 0,87 & 4,84 & 47 & 68 & 83 \\
\hline Campos e áreas verdes & 7,21 & 40,19 & 8,53 & 47,55 & 5,54 & 30,88 & 67 & 83 & 92 \\
\hline Floresta Ombrófila Mista Aluvial & 2,08 & 11,59 & 0,03 & 0,17 & 1,08 & 6,04 & 69 & 84 & 92 \\
\hline Uso da Terra Agricultura & 0,50 & 2,79 & 1,85 & 10,31 & 2,05 & 11,44 & 75 & 88 & 94 \\
\hline Áreas Urbanas & 2,17 & 12,10 & 1,97 & 10,98 & 3,12 & 17,37 & 83 & 92 & 96 \\
\hline Áreas com água & 0,00 & 0,00 & 0,00 & 0,00 & 0,82 & 4,57 & 100 & 100 & 100 \\
\hline Total de área da bacia & 17,94 & 100 & 17,94 & 100 & 17,94 & 100 & - & - & - \\
\hline CN média nas condições de umidade $\mathrm{NI}$ & 64 & - & 66 & - & 68 & - & - & - & - \\
\hline CN média nas condições de umidade NII & 81 & - & 82 & - & 83 & - & - & - & - \\
\hline CN média nas condições de umidade NIII & 90 & - & 91 & - & 92 & - & - & - & - \\
\hline
\end{tabular}

Com o valor já determinado da curva número e da intensidade da chuva calculou-se, através da Equação 2, os valores para a precipitação excedente 
$\left(P_{e}\right)$ para os anos de 1976, 1984 e 2009 em tempos de recorrência igual a 3, 5, 10, 15, 20, 25 e 50 anos (QUADRO 2).

\section{QUADRO 2 - Valor da Precipitação Excedente (Pe)}

\begin{tabular}{|c|c|c|c|c|c|c|c|c|c|c|c|}
\hline \multirow{2}{*}{$\begin{array}{l}\text { TEMPO } \\
\text { DURAÇÃO } \\
\text { td (min) }\end{array}$} & \multirow[t]{2}{*}{$\begin{array}{l}\text { TEMPO } \\
\text { DURAÇÃO } \\
\text { td }(h)\end{array}$} & \multirow[t]{2}{*}{$\begin{array}{c}\text { PRECIPITAÇÃO } \\
\text { Pt }(\mathrm{mm})\end{array}$} & \multicolumn{3}{|c|}{$\begin{array}{l}\text { PRECIPITAÇÃO } \\
\text { EFETIVA Pe }(\mathrm{mm}) \\
\text { CONDIÇÃO } \mathrm{NI}\end{array}$} & \multicolumn{3}{|c|}{$\begin{array}{l}\text { PRECIPITAÇÃO } \\
\text { EFETIVA Pe }(\mathrm{mm}) \\
\text { CONDIÇÃO NII }\end{array}$} & \multicolumn{3}{|c|}{$\begin{array}{l}\text { PRECIPITAÇÃO } \\
\text { EFETIVA Pe }(\mathrm{mm}) \\
\text { CONDIÇÃO } \mathrm{NIII}\end{array}$} \\
\hline & & & 1976 & 1984 & 2009 & 1976 & 1984 & 2009 & 1976 & 1984 & 2009 \\
\hline \multicolumn{12}{|l|}{$\operatorname{Tr} 3$ anos } \\
\hline 20 & 0,33 & 26,04 & 0,01 & 0,01 & 0,09 & 2,71 & 3,14 & 3,61 & 8,55 & 9,57 & 10,69 \\
\hline 40 & 0,67 & 36,47 & 0,57 & 0,96 & 1,46 & 7,17 & 7,91 & 8,70 & 16,09 & 17,48 & 18,98 \\
\hline 60 & 1,00 & 42,04 & 1,42 & 2,04 & 2,77 & 10,12 & 11,01 & 11,96 & 20,50 & 22,05 & 23,71 \\
\hline 80 & 1,33 & 45,85 & 2,20 & 2,97 & 3,87 & 12,32 & 13,31 & 14,37 & 23,63 & 25,28 & 27,03 \\
\hline 120 & 2,00 & 49,69 & 3,56 & 4,55 & 5,67 & 15,65 & 16,78 & 17,97 & 28,18 & 29,96 & 31,83 \\
\hline 180 & 3,00 & 56,28 & 5,05 & 6,25 & 7,58 & 18,93 & 20,19 & 21,49 & 32,51 & 34,39 & 36,37 \\
\hline 240 & 4,00 & 59,71 & 6,19 & 7,53 & 9,01 & 21,28 & 22,61 & 23,99 & 35,53 & 37,48 & 39,51 \\
\hline 300 & 5,00 & 62,33 & 7,12 & 8,57 & 10,16 & 23,11 & 24,50 & 25,94 & 37,85 & 39,84 & 41,93 \\
\hline \multicolumn{12}{|l|}{$\operatorname{Tr} 5$ anos } \\
\hline 20 & 0,33 & 27,68 & 0,01 & 0,06 & 0,20 & 3,30 & 3,78 & 4,31 & 9,66 & 10,75 & 11,93 \\
\hline 40 & 0,67 & 38,78 & 0,88 & 1,36 & 1,96 & 8,35 & 9,15 & 10,01 & 17,89 & 19,35 & 20,91 \\
\hline 60 & 1,00 & 44,70 & 1,95 & 2,67 & 3,52 & 11,63 & 12,60 & 13,62 & 22,67 & 24,29 & 26,01 \\
\hline 80 & 1,33 & 48,75 & 2,89 & 3,78 & 4,80 & 14,07 & 15,14 & 16,27 & 26,05 & 27,77 & 29,59 \\
\hline 120 & 2,00 & 52,83 & 4,50 & 5,62 & 6,88 & 17,75 & 18,96 & 20,23 & 30,97 & 32,81 & 34,76 \\
\hline 180 & 3,00 & 59,83 & 6,23 & 7,58 & 9,06 & 21,36 & 22,69 & 24,08 & 35,63 & 37,58 & 39,62 \\
\hline 240 & 4,00 & 63,49 & 7,55 & 9,05 & 10,68 & 23,93 & 25,34 & 26,81 & 38,88 & 40,89 & 43,00 \\
\hline 300 & 5,00 & 66,27 & 8,62 & 10,23 & 11,98 & 25,93 & 27,40 & 28,93 & 41,37 & 43,43 & 45,58 \\
\hline \multicolumn{12}{|l|}{$\operatorname{Tr} 10$ anos } \\
\hline 20 & 0,33 & 30,08 & 0,05 & 0,20 & 0,43 & 4,25 & 4,80 & 5,40 & 11,34 & 12,51 & 13,79 \\
\hline 40 & 0,67 & 42,14 & 1,44 & 2,06 & 2,80 & 10,17 & 11,07 & 12,02 & 20,58 & 22,13 & 23,79 \\
\hline 60 & 1,00 & 48,57 & 2,85 & 3,73 & 4,74 & 13,96 & 15,03 & 16,15 & 25,90 & 27,62 & 29,43 \\
\hline 80 & 1,33 & 52,98 & 4,04 & 5,11 & 6,30 & 16,75 & 17,93 & 19,16 & 29,66 & 31,47 & 33,38 \\
\hline 120 & 2,00 & 57,42 & 6,02 & 7,34 & 8,80 & 20,94 & 22,25 & 23,63 & 35,09 & 37,03 & 39,06 \\
\hline 180 & 3,00 & 65,02 & 8,13 & 9,69 & 11,39 & 25,03 & 26,47 & 27,97 & 40,25 & 42,29 & 44,42 \\
\hline 240 & 4,00 & 69,00 & 9,72 & 11,44 & 13,30 & 27,93 & 29,45 & 31,04 & 43,83 & 45,93 & 48,12 \\
\hline 300 & 5,00 & 72,02 & 11,00 & 12,84 & 14,82 & 30,18 & 31,77 & 33,41 & 46,57 & 48,73 & 50,96 \\
\hline \multicolumn{12}{|l|}{$\operatorname{Tr} 15$ anos } \\
\hline 20 & 0,33 & 31,58 & 0,13 & 0,33 & 0,62 & 4,88 & 5,48 & 6,13 & 12,42 & 13,65 & 14,98 \\
\hline 40 & 0,67 & 44,24 & 1,86 & 2,56 & 3,38 & 11,37 & 12,32 & 13,33 & 22,29 & 23,90 & 25,61 \\
\hline 60 & 1,00 & 51,00 & 3,48 & 4,47 & 5,58 & 15,48 & 16,61 & 17,79 & 27,96 & 29,73 & 31,60 \\
\hline 80 & 1,33 & 55,62 & 4,84 & 6,01 & 7,32 & 18,49 & 19,73 & 21,03 & 31,94 & 33,81 & 35,77 \\
\hline 120 & 2,00 & 60,28 & 7,07 & 8,51 & 10,09 & 23,00 & 24,38 & 25,83 & 37,71 & 39,70 & 41,79 \\
\hline 180 & 3,00 & 68,27 & 9,42 & 11,11 & 12,94 & 27,39 & 28,90 & 30,47 & 43,17 & 45,26 & 47,44 \\
\hline 240 & 4,00 & 72,44 & 11,18 & 13,03 & 15,03 & 30,50 & 32,09 & 33,74 & 46,95 & 49,11 & 51,35 \\
\hline 300 & 5,00 & 75,61 & 12,59 & 14,57 & 16,70 & 32,91 & 34,56 & 36,27 & 49,86 & 52,06 & 54,34 \\
\hline \multicolumn{12}{|l|}{$\operatorname{Tr} 20$ anos } \\
\hline 20 & 0,33 & 32,69 & 0,20 & 0,44 & 0,79 & 5,37 & 6,00 & 6,68 & 13,24 & 14,50 & 15,87 \\
\hline 40 & 0,67 & 45,79 & 2,19 & 2,96 & 3,85 & 12,28 & 13,28 & 14,33 & 23,58 & 25,23 & 26,98 \\
\hline 60 & 1,00 & 52,79 & 3,99 & 5,04 & 6,23 & 16,63 & 17,80 & 19,03 & 29,49 & 31,30 & 33,21 \\
\hline 80 & 1,33 & 57,58 & 5,47 & 6,72 & 8,11 & 19,81 & 21,09 & 22,43 & 33,65 & 35,56 & 37,55 \\
\hline 120 & 2,00 & 62,40 & 7,88 & 9,41 & 11,08 & 24,55 & 25,98 & 27,47 & 39,65 & 41,69 & 43,80 \\
\hline 180 & 3,00 & 70,66 & 10,42 & 12,20 & 14,13 & 29,17 & 30,73 & 32,34 & 45,34 & 47,47 & 49,68 \\
\hline 240 & 4,00 & 74,98 & 12,30 & 14,26 & 16,36 & 32,43 & 34,07 & 35,76 & 49,28 & 51,47 & 53,74 \\
\hline 300 & 5,00 & 78,27 & 13,81 & 15,90 & 18,13 & 34,96 & 36,66 & 38,41 & 52,30 & 54,54 & 56,85 \\
\hline $\operatorname{Tr} 25$ anos & & & & & & & & & & & \\
\hline 20 & 0,33 & 33,58 & 0,27 & 0,55 & 0,93 & 5,78 & 6,43 & 7,14 & 13,90 & 15,19 & 16,59 \\
\hline 40 & 0,67 & 47,04 & 2,48 & 3,29 & 4,24 & 13,02 & 14,05 & 15,14 & \begin{tabular}{|l|}
24,61 \\
\end{tabular} & 26,29 & 28,07 \\
\hline 60 & 1,00 & 54,22 & 4,41 & 5,53 & 6,77 & 17,57 & 18,77 & 20,03 & 30,72 & 32,57 & 34,50 \\
\hline 80 & 1,33 & 59,14 & 5,99 & 7,31 & 8,77 & 20,88 & 22,20 & 23,57 & 35,02 & 36,96 & 38,99 \\
\hline 120 & 2,00 & 64,09 & 8,56 & 10,16 & 11,90 & 25,81 & 27,28 & 28,80 & 41,22 & 43,29 & 45,43 \\
\hline 180 & 3,00 & 72,58 & 11,24 & 13,10 & 15,11 & 30,61 & 32,20 & 33,85 & 47,09 & 49,25 & 51,48 \\
\hline 240 & 4,00 & 77,02 & 13,23 & 15,27 & 17,45 & 33,99 & 35,67 & 37,40 & 51,15 & 53,37 & 55,66 \\
\hline 300 & 5,00 & 80,39 & 14,82 & 16,99 & 19,30 & 36,62 & 38,36 & 40,15 & 54,26 & 56,53 & 58,86 \\
\hline $\operatorname{Tr} 50$ anos & & & & & & & & & & & \\
\hline 20 & 0,33 & 36,49 & 0,57 & 0,96 & 1,46 & 7,18 & 7,92 & 8,71 & 16,11 & 17,50 & 19,00 \\
\hline 40 & 0,67 & 51,12 & 3,52 & 4,50 & 5,62 & 15,56 & 16,69 & 17,87 & 28,06 & 29,83 & 31,70 \\
\hline 60 & 1,00 & 58,92 & 5,92 & 7,23 & 8,68 & 20,73 & 22,04 & 23,41 & 34,83 & 36,76 & 38,79 \\
\hline 80 & 1,33 & 64,27 & 7,85 & 9,37 & 11,04 & 24,49 & 25,91 & 27,40 & 39,57 & 41,60 & 43,72 \\
\hline 120 & 2,00 & 69,65 & 10,92 & 12,75 & 14,73 & 30,05 & 31,63 & 33,27 & 46,41 & 48,56 & 50,79 \\
\hline 180 & 3,00 & 78,88 & 14,10 & 16,21 & 18,46 & 35,43 & 37,15 & 38,91 & 52,86 & 55,11 & 57,43 \\
\hline 240 & 4,00 & 83,70 & 16,44 & 18,73 & 21,18 & 39,22 & 41,02 & 42,86 & 57,32 & 59,63 & 62,00 \\
\hline 300 & 5,00 & 87,36 & 18,30 & 20,74 & 23,32 & 42,16 & 44,01 & 45,92 & 60,74 & 63,09 & 65,50 \\
\hline
\end{tabular}


Segundo Fendrich (2008, p. 40) o fator de redução de pico (Z), um dos coeficientes para o cálculo médio da vazão, é a relação entre a vazão de pico de um hidrograma unitário e o escoamento da mesma intensidade da chuva. Para determinar o valor de " $Z$ " Ven Te Chow buscou a relação do tempo de duração da chuva pela razão com o tempo de pico da vazão máxima definida na (Equação 6).

$$
T=0,005055 \cdot\left(\frac{L}{\sqrt{I}}\right)^{0,64}
$$

equação 6

onde:

$\mathrm{T}=$ tempo de pico $(\mathrm{h})$;

$\mathrm{L}$ = comprimento do curso d'água, medido desde a seção de projeto até o ponto mais afastado da bacia de drenagem $(\mathrm{m})$, sendo igual a $8.559 \mathrm{~m}$ para a bacia do Rio Canguri e;

$\mathrm{I}$ = declividade média do curso d'água, sendo igual a $0,817 \%$ para o rio Canguiri

A declividade média do curso d'água para o Rio Canguiri foi calculada através do perfil longitudinal do rio principal (Figura 5).

$$
I=((955-885) \times 100) / 8.8559 \text {,sendo } I=0,817 \%
$$

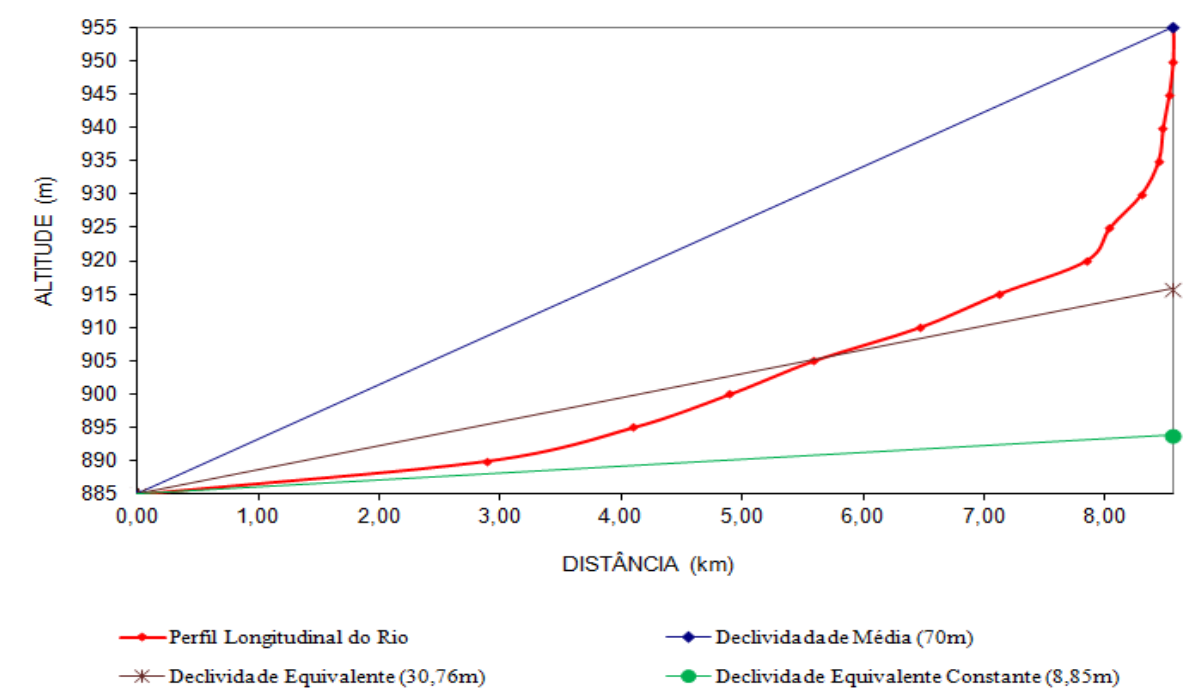

FIGURA 5 - Perfil Longitudinal do Rio Canguiri

O fator de redução de pico da vazão " $Z$ " é em função da relação entre a duração da chuva "td" e o tempo de pico "T" e pode ser observado no Quadro (3) de acordo com Fendrich (2008, p.41) citando Wilken (1978). Tendo o tempo de pico igual a $T=1,77$ horas, podem-se obter os valores de $Z$ nos tempos de 
duração 20 a 240 minutos Tabela (4), notando-se que em alguns casos foi preciso interpolar os valores de $Z$, pois alguns valores da razão $\mathrm{td} / \mathrm{T}$ não estão definidos na tabela dos fatores de redução " $Z$ ".

QUADRO 3 - Fatores de Redução de Pico da Vazão - Z

\begin{tabular}{|c|l|l|l|l|l|l|l|l|l||}
\hline $\mathbf{t d} / \mathbf{T}$ & $\mathbf{Z}$ & $\mathbf{t d} / \mathbf{T}$ & $\mathbf{Z}$ & $\mathbf{t d} / \mathbf{T}$ & $\mathbf{Z}$ & $\mathbf{t d} / \mathbf{T}$ & $\mathbf{Z}$ & $\mathbf{t d} / \mathbf{T}$ & $\mathbf{Z}$ \\
\hline 0,05 & 0,04 & 0,46 & 0,36 & 0,84 & 0,58 & 1,22 & 0,75 & 1,60 & 0,90 \\
0,10 & 0,08 & 0,48 & 0,38 & 0,86 & 0,59 & 1,24 & 0,76 & 1,62 & 0,90 \\
0,12 & 0,10 & 0,50 & 0,39 & 0,88 & 0,59 & 1,26 & 0,77 & 1,64 & 0,91 \\
0,14 & 0,12 & 0,52 & 0,40 & 0,90 & 0,60 & 1,28 & 0,78 & 1,66 & 0,91 \\
0,16 & 0,14 & 0,54 & 0,41 & 0,92 & 0,61 & 1,30 & 0,79 & 1,68 \\
0,18 & 0,16 & 0,56 & 0,42 & 0,94 & 0,62 & 1,32 & 0,80 & 0,92 \\
0,20 & 0,18 & 0,58 & 0,44 & 0,96 & 0,63 & 1,34 & 0,81 & 1,72 \\
0,22 & 0,19 & 0,60 & 0,45 & 0,98 & 0,64 & 1,36 & 0,82 & 0,92 \\
0,24 & 0,20 & 0,62 & 0,46 & 1,00 & 0,65 & 1,38 & 0,82 & 1,74 & 0,93 \\
0,26 & 0,22 & 0,64 & 0,47 & 1,02 & 0,66 & 1,40 & 0,82 & 1,78 \\
0,28 & 0,24 & 0,66 & 0,48 & 1,04 & 0,67 & 1,42 & 0,83 & 0,94 \\
0,30 & 0,25 & 0,68 & 0,49 & 1,06 & 0,68 & 1,44 & 0,84 & 0,94 \\
0,32 & 0,26 & 0,70 & 0,50 & 1,08 & 0,69 & 1,46 & 0,85 & 1,82 \\
0,34 & 0,28 & 0,72 & 0,51 & 1,10 & 0,70 & 1,48 & 0,86 & 0,95 \\
0,36 & 0,29 & 0,74 & 0,52 & 1,12 & 0,71 & 1,50 & 0,86 & 1,84 \\
0,38 & 0,30 & 0,76 & 0,54 & 1,14 & 0,72 & 1,52 & 0,87 & 0,96 \\
0,40 & 0,32 & 0,78 & 0,55 & 1,16 & 0,73 & 1,54 & 0,88 & 0,96 \\
0,42 & 0,33 & 0,80 & 0,56 & 1,18 & 0,74 & 1,56 & 0,88 & 0,97 \\
0,44 & 0,34 & 0,82 & 0,57 & 1,20 & 0,74 & 1,58 & 0,89 & 1,92 \\
\hline
\end{tabular}

Fonte Fendrich, 2008

\begin{tabular}{|c|c|c|c|}
\hline $\mathrm{td}$ (minutos) & td (horas) & $\mathrm{td} / \mathrm{T}$ & Z (tabelado) \\
\hline 20 & 0,33 & 0,19 & 0,17 \\
\hline 40 & 0,67 & 0,38 & 0,30 \\
\hline 60 & 1 & 0,56 & 0,42 \\
\hline 80 & 1,33 & 0,75 & 0,53 \\
\hline 120 & 2 & 1,13 & 0,72 \\
\hline 180 & 3 & 1,69 & 0,92 \\
\hline 240 & 4 & 2.26 & 1,00 \\
\hline 300 & 5 & 2,82 & 1,00 \\
\hline
\end{tabular}

\section{RESULTADOS E DISCUSSÃO}

$\mathrm{Na}$ Figura (6) pode-se observar a relação entre as tipologias de uso do solo. A Floresta Ombrófila Mista Montana foi à tipologia que maior modificação apresentou, constando para o ano de 2009 apenas 51,40 \% (21,38\% para $10,36 \%)$ da área de floresta verificada em 1976, correspondendo a uma redução média de 5,76 ha/ano. A área com agricultura aumentou 8,7\% de 1976 para 2009. A área urbana teve um acréscimo de 43,80\% em 2009 comparado com o ano de 1976.

As áreas de vegetação secundária aumentam $0,45 \mathrm{~km}^{2}$ em 2009 quando comparada com 1976; estepe gramíneo lenhosa reduz uma área de 
1,67 km² e a Floresta Ombrófila Mista Montana também reduz sua área em

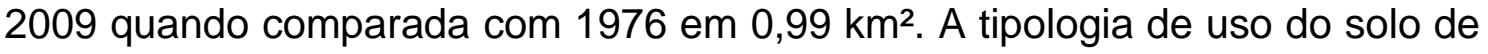
áreas com água que em 1976 é igual a zero em 2009 é igual a 0,82 km² devido à criação da Represa do Iraí.

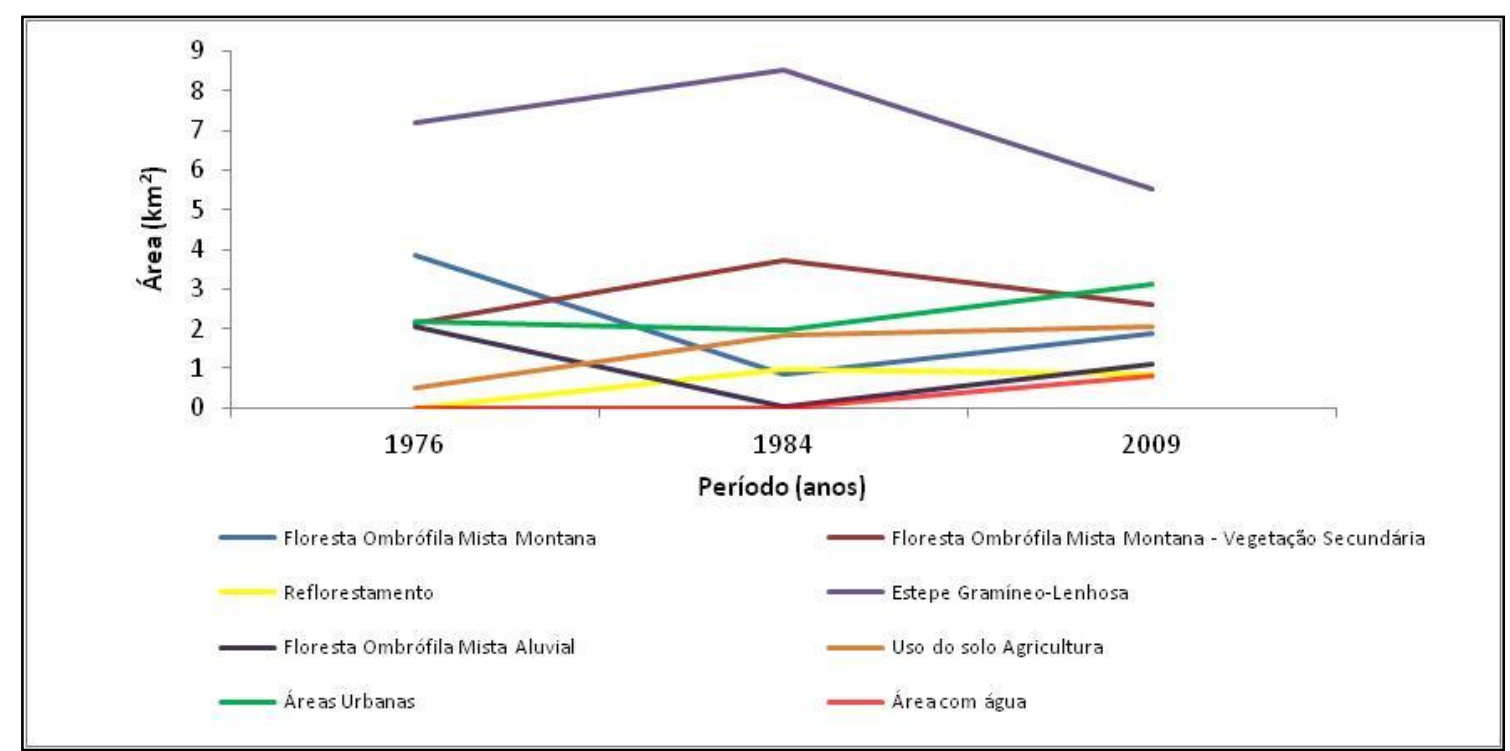

FIGURA 6 - Dinâmica dos Usos do Solo na Bacia do Rio Canguiri

Foi calculada a vazão de pico pelo método de Ven Te Chow, conforme Equação 1, para tempo de duração igual a 20, 40, 60, 80, 120, 180, 240 e 300 minutos e para os tempos de recorrência de 3, 5, 10, 15, 20, 25 e 50 anos nas diferentes condições de umidades antecedentes.

No Quadro (4) está à relação da vazão de pico entre os anos de 1976, 1984 e 2009. Nota-se que a vazão de pico alternou entre os tempos de duração de 180 e 120 minutos e aumentou com o passar dos anos. O aumento da vazão está relacionado ao aumento do escoamento superficial causado pela impermeabilização do solo o qual é diretamente influenciado pela redução das florestas e crescimento da área urbana.

Comparando os picos de vazões na condição NIII de umidade antecedente do solo, onde o solo encontra-se quase saturado e mais propício para formação de grandes cheias (Baugarten; Felix; Müller, 2003, p. 06), com td $=2,00$ e $T r=3$, tem-se que $Q_{\max }=51,46 \mathrm{~m}^{3} / \mathrm{s}$ para $1976, Q_{\max }=53,63 \mathrm{~m}^{3} / \mathrm{s}$ para 1984 e $Q_{\max }=56,98 \mathrm{~m}^{3} / \mathrm{s}$ para 2009, nota-se uma diferença crescente de $2,17 \mathrm{~m}^{3} / \mathrm{s}$ entre 1976 e 1984 e de $3,35 \mathrm{~m}^{3} / \mathrm{s}$ entre 1984 e 2009 . 
QUADRO 4 - Vazão Máxima Calculada pelo Método de Ven Te Chow

\begin{tabular}{|c|c|c|c|c|c|c|c|c|c|c|}
\hline \multirow{3}{*}{$\begin{array}{c}\text { td } \\
\text { (minutos) }\end{array}$} & \multirow{3}{*}{$\begin{array}{c}\text { td } \\
\text { (horas) }\end{array}$} & \multicolumn{3}{|c|}{$\mathrm{NI}$} & \multicolumn{3}{|c|}{$\mathrm{NII}$} & \multicolumn{3}{|c|}{ NIII } \\
\hline & & 1976 & 1984 & 2009 & 1976 & 1984 & 2009 & 1976 & 1984 & 2009 \\
\hline & & $\begin{array}{c}\text { Qmáx } \\
\left(m^{3} \cdot s^{-1}\right)\end{array}$ & $\begin{array}{c}\text { Qmáx } \\
\left(m^{3} . s^{-1}\right)\end{array}$ & $\begin{array}{c}\text { Qmáx } \\
\left(m^{3} \cdot s^{-1}\right)\end{array}$ & $\begin{array}{c}\text { Qmáx } \\
\left(m^{3} \cdot s^{-1}\right)\end{array}$ & $\begin{array}{c}\text { Qmáx } \\
\left(m^{3} \cdot s^{-1}\right)\end{array}$ & $\begin{array}{c}\text { Qmáx } \\
\left(m^{3} \cdot s^{-1}\right)\end{array}$ & $\begin{array}{c}\text { Qmáx } \\
\left(m^{3} \cdot s^{-1}\right)\end{array}$ & $\begin{array}{c}\text { Qmáx } \\
\left(m^{3} \cdot s^{-1}\right)\end{array}$ & $\underset{\left(m^{3} . s^{-1}\right)}{\text { Qmáx }}$ \\
\hline \multicolumn{11}{|l|}{$\operatorname{Tr} 3$} \\
\hline 20 & 0,33 & 0,03 & 0,02 & 0,23 & 6,93 & 8,03 & 9,25 & 21,91 & 24,51 & 27,39 \\
\hline 40 & 0,67 & 1,27 & 2,14 & 3,25 & 15,95 & 17,60 & 19,37 & 35,83 & 38,92 & 42,25 \\
\hline 60 & 1,00 & 2,97 & 4,26 & 5,78 & 21,13 & 23,00 & 24,98 & 42,81 & 46,05 & 49,50 \\
\hline 80 & 1,33 & 4,37 & 5,89 & 7,66 & 24,40 & 26,38 & 28,46 & 46,81 & 50,08 & 53,55 \\
\hline 120 & 2,00 & 6,37 & 8,14 & 10,15 & 28,01 & 30,04 & 32,17 & 51,46 & 53,63 & 56,98 \\
\hline 180 & 3,00 & 7,70 & 9,53 & 11,56 & 28,87 & 30,78 & 32,78 & 49,57 & 52,45 & 55,46 \\
\hline 240 & 4,00 & 7,70 & 9,36 & 11,20 & 26,45 & 28,10 & 29,83 & 44,16 & 46,59 & 49,12 \\
\hline 300 & 5,00 & 7,08 & 8,52 & 10,10 & 22,98 & 24,36 & 25,80 & 37,64 & 39,62 & 41,69 \\
\hline \multicolumn{11}{|l|}{$\operatorname{Tr} 5$} \\
\hline 20 & 0,33 & 0,03 & 0,14 & 0,51 & 8,45 & 9,68 & 11,03 & 24,75 & 27,52 & 30,57 \\
\hline 40 & 0,67 & 1,96 & 3,03 & 4,36 & 18,58 & 20,38 & 22,29 & 39,83 & 43,08 & 46,56 \\
\hline 60 & 1,00 & 4,08 & 5,58 & 7,35 & 24,30 & 26,32 & 28,45 & 47,34 & 50,73 & 54,33 \\
\hline 80 & 1,33 & 5,74 & 7,50 & 9,51 & 27,88 & 30,01 & 32,24 & 51,62 & 55,03 & 58,63 \\
\hline 120 & 2,00 & 8,05 & 10,06 & 12,32 & 31,77 & 33,94 & 36,21 & 56,54 & 58,74 & 62,21 \\
\hline 180 & 3,00 & 9,50 & 11,56 & 13,82 & 32,57 & 34,60 & 36,72 & 54,33 & 57,31 & 60,42 \\
\hline 240 & 4,00 & 9,39 & 11,25 & 13,28 & 29,75 & 31,50 & 33,33 & 48,33 & 50,83 & 53,45 \\
\hline 300 & 5,00 & 8,57 & 10,17 & 11,91 & 25,79 & 27,25 & 28,77 & 41,14 & 43,19 & 45,33 \\
\hline \multicolumn{11}{|l|}{$\operatorname{Tr} 10$} \\
\hline 20 & 0,33 & 0,14 & 0,50 & 1,11 & 10,87 & 12,29 & 13,83 & 29,05 & 32,05 & 35,33 \\
\hline 40 & 0,67 & 3,21 & 4,59 & 6,22 & 22,64 & 24,64 & 26,77 & 45,82 & 49,28 & 52,97 \\
\hline 60 & 1,00 & 5,95 & 7,79 & 9,90 & 29,16 & 31,39 & 33,73 & 54,09 & 57,68 & 61,47 \\
\hline 80 & 1,33 & 8,01 & 10,12 & 12,49 & 33,20 & 35,53 & 37,97 & 58,76 & 62,36 & 66,14 \\
\hline 120 & 2,00 & 10,78 & 13,14 & 15,75 & 37,47 & 39,84 & 42,30 & 64,07 & 66,29 & 69,92 \\
\hline 180 & 3,00 & 12,40 & 14,78 & 17,37 & 38,16 & 40,37 & 42,66 & 61,37 & 64,49 & 67,73 \\
\hline 240 & 4,00 & 12,08 & 14,22 & 16,53 & 34,72 & 36,61 & 38,58 & 54,48 & 57,10 & 59,82 \\
\hline 300 & 5,00 & 10,94 & 12,76 & 14,74 & 30,02 & 31,59 & 33,22 & 46,32 & 48,46 & 50,67 \\
\hline \multicolumn{11}{|l|}{$\operatorname{Tr} 15$} \\
\hline 20 & 0,33 & 0,32 & 0,84 & 1,60 & 12,50 & 14,04 & 15,69 & 31,82 & 34,96 & 38,38 \\
\hline 40 & 0,67 & 4,13 & 5,70 & 7,53 & 25,31 & 27,44 & 29,68 & 49,63 & 53,22 & 57,03 \\
\hline 60 & 1,00 & 7,28 & 9,33 & 11,65 & 32,33 & 34,68 & 37,15 & 58,38 & 62,08 & 65,98 \\
\hline 80 & 1,33 & 9,59 & 11,92 & 14,51 & 36,64 & 39,10 & 41,66 & 63,29 & 66,99 & 70,88 \\
\hline 120 & 2,00 & 12,65 & 15,23 & 18,07 & 41,17 & 43,65 & 46,23 & 68,86 & 71,07 & 74,80 \\
\hline 180 & 3,00 & 14,36 & 16,94 & 19,73 & 41,76 & 44,07 & 46,46 & 65,82 & 69,02 & 72,34 \\
\hline 240 & 4,00 & 13,89 & 16,20 & 18,69 & 37,91 & 39,89 & 41,94 & 58,36 & 61,05 & 63,83 \\
\hline 300 & 5,00 & 12,52 & 14,49 & 16,60 & 32,73 & 34,37 & 36,07 & 49,58 & 51,77 & 54,04 \\
\hline \multicolumn{11}{|l|}{$\operatorname{Tr} 20$} \\
\hline 20 & 0,33 & 0,51 & 1,14 & 2,01 & 13,76 & 15,38 & 17,12 & 33,91 & 37,15 & 40,66 \\
\hline 40 & 0,67 & 4,88 & 6,59 & 8,57 & 27,34 & 29,56 & 31,90 & 52,49 & 56,16 & 60,06 \\
\hline 60 & 1,00 & 8,33 & 10,53 & 13,01 & 34,73 & 37,17 & 39,73 & 61,58 & 65,37 & 69,35 \\
\hline 80 & 1,33 & 10,84 & 13,32 & 16,07 & 39,25 & 41,79 & 44,45 & 66,67 & 70,45 & 74,41 \\
\hline 120 & 2,00 & 14,11 & 16,85 & 19,84 & 43,95 & 46,51 & 49,17 & 72,41 & 74,62 & 78,41 \\
\hline 180 & 3,00 & 15,88 & 18,60 & 21,55 & 44,47 & 46,85 & 49,31 & 69,13 & 72,39 & 75,76 \\
\hline 240 & 4,00 & 15,29 & 17,72 & 20,34 & 40,31 & 42,35 & 44,46 & 61,26 & 63,98 & 66,80 \\
\hline 300 & 5,00 & 13,74 & 15,81 & 18,03 & 34,77 & 36,46 & 38,20 & 52,01 & 54,24 & 56,53 \\
\hline \multicolumn{11}{|l|}{$\operatorname{Tr} 25$} \\
\hline 20 & 0,33 & 0,69 & 1,40 & 2,37 & 14,80 & 16,48 & 18,29 & 35,60 & 38,91 & 42,51 \\
\hline 40 & 0,67 & 5,51 & 7,33 & 9,44 & 29,00 & 31,28 & 33,70 & 54,79 & 58,53 & 62,50 \\
\hline 60 & 1,00 & 9,21 & 11,54 & 14,15 & 36,68 & 39,20 & 41,83 & 64,16 & 68,01 & 72,05 \\
\hline 80 & 1,33 & 11,88 & 14,49 & 17,37 & 41,37 & 43,98 & 46,70 & 69,39 & 73,23 & 77,25 \\
\hline 120 & 2,00 & 15,32 & 18,18 & 21,31 & 46,21 & 48,83 & 51,56 & 75,27 & 77,48 & 81,32 \\
\hline 180 & 3,00 & 17,14 & 19,98 & 23,04 & 46,67 & 49,10 & 51,62 & 71,80 & 75,09 & 78,50 \\
\hline 240 & 4,00 & 16,44 & 18,98 & 21,69 & 42,25 & 44,34 & 46,49 & 63,58 & 66,34 & 69,19 \\
\hline 300 & 5,00 & 14,74 & 16,89 & 19,20 & 36,41 & 38,14 & 39,92 & 53,96 & 56,21 & 58,54 \\
\hline $\operatorname{Tr} 50$ & & & & & & & & & & \\
\hline 20 & 0,33 & 1,47 & 2,47 & 3,75 & 18,38 & 20,28 & 22,32 & 41,26 & 44,82 & 48,66 \\
\hline 40 & 0,67 & 7,83 & 10,03 & 12,51 & 34,63 & 37,15 & 39,79 & 62,47 & 66,42 & 70,58 \\
\hline 60 & 1,00 & 12,36 & 15,09 & 18,12 & 43,29 & 46,03 & 48,89 & 72,73 & 76,77 & 81,00 \\
\hline 80 & 1,33 & 15,54 & 18,57 & 21,88 & 48,52 & 51,35 & 54,29 & 78,41 & 82,43 & 86,62 \\
\hline 120 & 2,00 & 19,54 & 22,82 & 26,36 & 53,79 & 56,62 & 59,55 & 84,74 & 86,92 & 90,91 \\
\hline 180 & 3,00 & 21,50 & 24,71 & 28,15 & 54,03 & 56,64 & 59,33 & 80,60 & 84,03 & 87,56 \\
\hline 240 & 4,00 & 20,43 & 23,29 & 26,32 & 48,76 & 50,99 & 53,28 & 71,26 & 74,12 & 77,07 \\
\hline 300 & 5,00 & 18,20 & 20,62 & 23,19 & 41,92 & 43,77 & 45,66 & 60,41 & 62,74 & 65,14 \\
\hline
\end{tabular}


A Figura 7 mostra o comportamento da vazão de pico, na condição normal de umidade do solo (NII), nos diferentes tempos de recorrência e períodos estudados. A falta de áreas florestadas, as quais reduzem o impacto da chuva no solo e aumenta a infiltração de água no solo e o aumento de áreas urbanizadas, que reduzem drasticamente a infiltração e eleva o escoamento superficial, causam a elevação da vazão de pico.

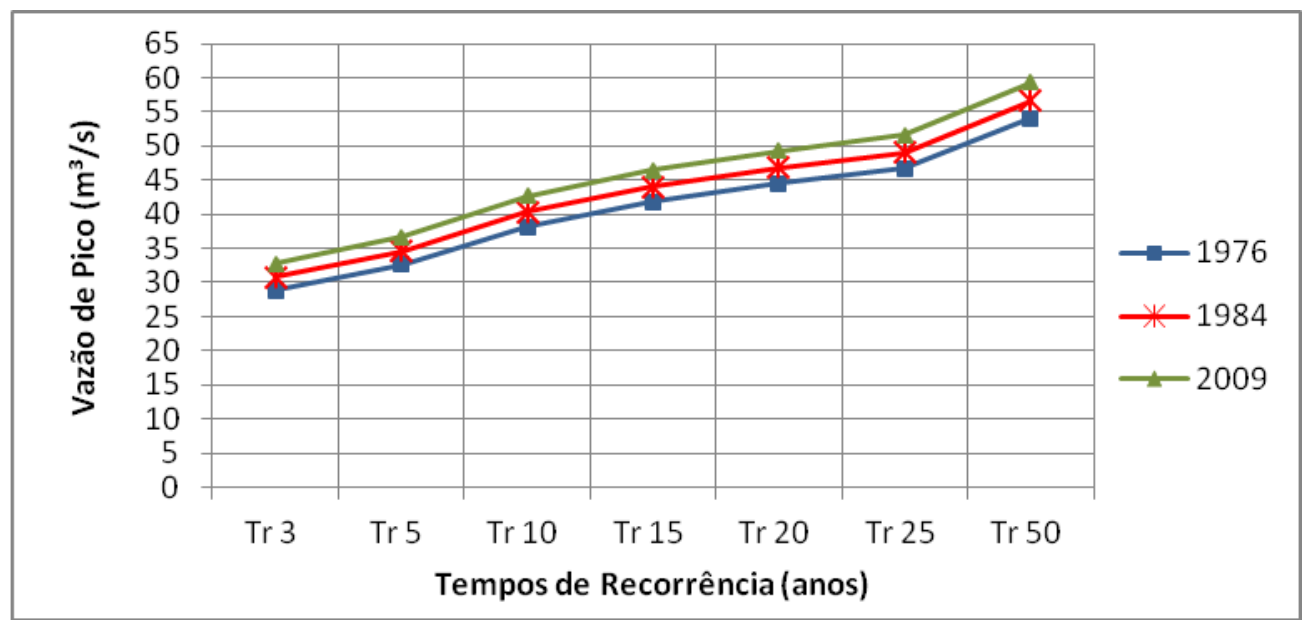

FIGURA 7 - Vazão de pico para a Condição NII de umidade antecedente do solo na Bacia Hidrográfica do Rio Canguiri

\section{CONCLUSÕES}

A bacia hidrográfica do Rio Canguiri sofreu um processo de urbanização entre o período de 1976 a 2009, verificando um acelerado adensamento de áreas urbanas e agricultura e redução das áreas de florestas.

O método Ven Te Chow - Soil Conservation Service (SCS) utilizando a Curva Número permitiu avaliar os impactos causados pelo mau uso do solo na resposta hidrológica da bacia, obtendo as vazões máximas ou de pico que podem ser utilizadas nos estudos das enchentes bem como avaliação, dimensionamento e planejamento de obras hidráulicas para proteção contra inundações nas bacias urbanizadas, como a bacia do Rio Canguiri.

As áreas das tipologias de uso do solo da Floresta Ombrófila Mista Montana, Estepe Gramíneo Lenhosa e a Floresta Ombrófila Mista Aluvial reduziram suas áreas em 2009 quando comparadas com as áreas em 1976. Já as tipologias de uso do solo da Vegetação Secundária, Reflorestamento, 
Agricultura, áreas urbanas e água, aumentaram sua área em 2009 quando comparadas com 1976.

As áreas urbanas que possuíam $12,10 \%$ de toda a área da bacia em 1976, em 2009 passam a ocupar 17,37\% de toda a área da bacia. A Floresta Ombrófila Mista Aluvial que em 1976 ocupava 11,53\% da bacia em 2009 passa a ocupar apenas 6\%. Em 1976 2,78\% da bacia eram ocupadas com agricultura em 2009 foi para 11, 44\%. A tipologia Floresta Ombrófila Mista Montana ocupava $21,40 \%$ da área da bacia hidrográfica em 2009 passou a ocupar apenas $10,36 \%$.

O aumento nas áreas urbanizadas e da agricultura e a redução de florestas refletem diretamente na elevação das vazões de pico, pois ha aumento da precipitação efetiva, ou escoamento superficial. Para um tempo de recorrência de 3 anos para condição normal de umidade a vazão de pico elevou-se de 28,87 m³/s em 1976 para 30,78 m³/s em 1984 e, para 32,78 m³/s em 2009. A mesma tendência de evolução da vazão acontece para os tempos de recorrência de 10, 15, 20, 25 e 50 .

\section{REFERENCIAS BIBLIOGRÁFICAS}

BHERING, Silvio Barge; SANTOS, Humberto Gonçalves dos. Mapa de Solos do Estado do Paraná, legenda atualizada. Rio de Janeiro - RJ, Embrapa Florestas, Embrapa Solos, Instituto Agronômico do Paraná, 2008.

BIGARELLA, João José; SALAMUNI, Riad. Caracteres texturais dos sedimentos da Bacia de Curitiba. Boletim da Universidade Federal do Paraná, Curitiba, 1962.

COMEC. Coordenação da Região Metropolitana de Curitiba. Disponível em (www.comec.pr.gov.br). Acesso em: 12 de maio de 2011.

DEPARTAMENTO DE ÁGUAS E ENERGIA ELÉTRICA (DAEE). Tentativa de avaliação do escoamento superficial de acordo com o solo e o seu recobrimento vegetal nas condições do Estado de São Paulo. In: BOLETIM TÉCNICO DAEE, São Paulo - SP, v. 2, n. 2, p. 81-103, Maio/Ago. 1979.

FENDRICH, Roberto. Chuvas intensas para obras de drenagem no estado do Paraná. Curitiba: UFPR, 2003. 
FENDRICH, Roberto. Canais de drenagem de pequenas bacias hidrográficas. Curitiba: UFPR, 2008.

FELIPE, Rogério da Silva. Características Geológico-Geotécnicas da Formação Guabirotuba Curitiba. MINEROPAR, Serviço Geológico do Paraná, 1aㅡ edição, 49 p., 2011. Disponível em: < http://www.mineropar.pr.gov.br/arquivos/File/publicacoes/Caract_Geol_Geot_fo rmacao_Guabirotuba.pdf >. Acesso em: (15/04/2011).

GOMES, Julio; FENDRICH, Roberto h. A microinformática em projetos de macrodrenagem urbana. Relatório Técnico Final de Pesquisa. Curitiba - PR, 1991.

JABUR, Andrea Sartori. Estudo Hidrológico da Bacia Hidrográfica do Alto Rio Ligeiro, Pato Branco. 05 de julho de 2010. Tese de Doutorado em Manejo de Bacias Hidrográficas. Departamento de Pós-Graduação em Engenharia Florestal da Universidade Federal do Paraná - UFPR, Curitiba - PR.

JACOBS, Gerson Antonio. Dinâmica de Uso e Ocupação dos Mananciais na Região Metropolitana de Curitiba - PR. 28 de janeiro de 2002. Tese de Doutorado em Manejo de Bacias Hidrográficas. Departamento de PósGraduação em Engenharia Florestal da Universidade Federal do Paraná UFPR, Curitiba - PR.

MENDES FILHO, Walter Manoel; VENDRAME, Iria Fernandes; CARVALHO Ronaldo Gonçalves de. Utilização de sistema de informações geográficas para o mapeamento do potencial de retenção de águas pluviais no município de São José dos Campos - SP. In: SIMPÓSIO BRASILEIRO DE SENSORIAMENTO REMOTO, XIII, 2007, Florianópolis: INPE, 21-26 abril, p. 3453-3460.

NUNES, Fabrizia Gioppo; FIORI, Alberto Pio. A utilização do método de Ven Te Chow - Soil Conservation Service (SCS) na estimativa da vazão máxima da bacia hidrográfica do rio Atuba. Curitiba, julho/dezembro 2007. Disponível em: (www.ser.ufpr.br/geografar). Acesso em: (09/11/2010)

REYES, Daniel César Riveros. Análise das características hidrológicas de três sub-bacias do Rio Carapá (Canindeyú, Paraguai) em função das mudanças da cobertura vegetal em três diferentes épocas. 20 de abril de 2010.125f. Dissertação de Mestrado em Engenharia Florestal. Setor de Ciências Agrárias, Universidade Federal do Paraná, Curitiba - PR.

SARTORI, Anderson. Avaliação da Classificação Hidrológica do Solo para a Determinação do Excesso de Chuva do Método do Serviço de Conservação do Solo dos Estados Unidos. 20 de fevereiro de 2004. Dissertação de Mestrado em Engenharia Civil. Departamento de PósGraduação da Faculdade Engenharia Civil da Universidade Estadual de Campinas, São Paulo - SP. 
SENOGRAFIA Sensoriamento Remoto Ltda. Imagem Repideye (Período de 2009).

SOIL CONSERVATION SERVICE (SCS). In: DESIGN OF SMALL DAMS. 2 ed. United States Department of the Interior; Bureau of Reclamation, Washington DC, U.S.A., 816p., 1974.

SOIL SURVEY STAFF. Keys to Soil Taxonomy, Washington, DC: Natural Resources Conservation Service. $10^{\text {th }}$ ed 2006.

USBR U.S. Bureau of Reclamation - United States Department of the interior. Design of Small Dams. Companhia Editorial S.A. México, D. F., 639p., 1977

WILKEN, Paulo Sampaio. Engenharia de drenagem superficial. Companhia de Saneamento Ambiental - CTESB, São Paulo - SP, 1978.

Recebido em 30/08/2011.

Aceito em 20/06/2012. 